\title{
PENGARUH MOTIVASI DAN BEBAN KERJA TERHADAP KINERJA KARYAWAN DI RUMAH SAKIT NUR HIDAYAH BANTUL
}

\author{
Ahmad Ahid Mudayana \\ Fakultas Kesehatan Masyarakat, Universitas Ahmad Dahlan, Yogyakarta
}

\begin{abstract}
Background: : The process of development is a Nur Hidayah Hospital (RS Nur Hidayah) Bantul makes employees work load increases. Improved performance the hospital can improve employee performance. If the employees performance is getting better, the service given to the patients will be getting better too. While the employee's performance can be influenced by the work motivation. The researcher interested to do research the influence of motivation on performance of employees.

Objective: Measure of motivation and employee performance. Measure the influence of motivation on employee performance.

Method: this was quantitatif descriptive research using cross sectional approach plan. the number of 79 employees' respondents from 111 employees. The data analyzed using correlation analysis. Motivation assessed by questionnaire, performance while using a checklist.

Result and discussion: Motivation (82, 3\%) and performance (92, $4 \%$ ) employees are included in the high category. There is significant influence between motivation on employee performance $(r=0,775 p(0,00)<0,05)$. Influence of intrinsic motivation $(r=0,737)$ more powerful than extrinsic motivation $(r=0,325)$. There is influence of the sub variables of responsibility $(p=0,032)$, recognition $(p=0,002)$, work achievement $(p=0,007)$, career development $(p=0,000)$, work $(p=0,016)$, promotion $(p=0,029)$, work condition $(p=0,001)$ on employee performance.

Conclusion and recommendation: This study shows motivation and employee performance is already high. Overall there is a strong influence on employee work motivation Nur Hidayah Hospital Bantul. Work motivation still need to be maintained and improved for the better employee performance.
\end{abstract}

Keywords: Motivation, intrinsic motivation, extrinsic motivation, performance

\section{PENDAHULUAN}

Penilaian kinerja merupakan proses kontrol kinerja karyawan yang dievaluasi berdasarkan standar tertentu. Penilaian kinerja dilakukan secara efektif untuk mengarahkan perilaku perawat dalam rangka menghasilkan jasa dengan kualitas yang tinggi. Selain itu, penilaian kinerja juga dilakukan untuk memotivasi karyawan melakukan tugas-tugasnya dan mewujudkan tujuan rumah sakit. ${ }^{1}$

Manfaat dari penilain kinerja digunakan untuk perbaikan prestasi kerja, penyesuaian kompensasi, kebutuhan pengembangan, serta melihat penyimpangan maupun kesalahan dalam pekerjaan. Kegunaan tersebut mengharuskan penilaian kinerja mampu memberikan gambaran yang akurat dan obyektif mengenai prestasi kerja karyawan. ${ }^{2}$

Hasil observasi yang sudah dilakukan sebelumnya oleh peneliti pada saat magang mengenai kinerja karyawan di Rumah Sakit Nur Hidayah (RS Nur Hidayah) Kabupaten Bantul menunjukkan bahwa karyawan mempunyai peran penting dalam memberikan pelayanan kesehatan di rumah sakit tersebut. Di tunjukkan dengan naiknya BOR setiap tahun dengan rata-rata BOR mencapai $87,94 \%$ yang menandakan bahwa kinerja rumah sakit mengalami peningkatan. Meningkatnya kinerja rumah sakit dapat dipengaruhi oleh meningkatnya kinerja karyawan. RS Nur Hidayah yang saat ini 
memiliki 20 tempat tidur dengan jumlah karyawan tetap dan tidak tetap mencapai 111 orang. Dalam proses pengembangannya RS Nur Hidayah pada tahun 2010 ini akan dikonversi menjadi rumah sakit umum dengan 50 tempat tidur sehingga akan ada penambahan karyawan sesuai kebutuhan dan kemampuan rumah sakit.

Di samping itu, masih ada beberapa karyawan yang dibebani tugas ganda karena keterbatasan sumber daya yang dimiliki sehingga banyak karyawan yang masih merangkap jabatan dan tugas. Banyaknya tugas dan tanggung jawab yang diberikan kepada karyawan menyebabkan hasil yang dicapai menjadi kurang maksimal karena karyawan hanya mempunyai waktu yang sedikit untuk menyelesaikan banyak tugas. Belum dilaksanakannya job description yang sudah dibuat secara maksimal oleh karyawan rumah sakit akan berdampak pada hasil penilaian kinerja sebagai bahan evaluasi bagi manajemen rumah sakit. Perlu dilakukan upaya untuk memotivasi karyawan agar mampu melaksanakan tugasnya dengan baik sesuai job description yang sudah ditetapkan. Apabila ini tidak dilakukan maka akan berdampak pada penurunan kualitas kerja serta menurunnya kualitas pelayanan kesehatan yang selama ini sudah cukup baik. Upaya memotivasi dilakukan untuk meningkatkan prestasi kerja karyawan sesuai dengan tugasnya masing-masing.

Karyawan di RSKB Nur Hidayah saat ini ada pengembangan karier melalui program pelatihan dan pendidikan kejenjang yang lebih tinggi. Kesempatan untuk mengikuti program pengembangan tersebut masih terbatas dan tidak semua karyawan mempunyai kesempatan yang sama. Karyawan juga tidak diberikan reward secara langsung atas prestasi yang sudah didapat sehingga tidak ada pengakuan atas prestasi. Meskipun ada sistem penghitungan poin untuk penambahan jasa yang diberikan diakhir tahun sebagai bentuk penghargaan yang diberikan secara tidak langsung. Selain itu, kesempatan untuk promosi kejenjang yahg lebih tinggi masih sangat terbatas meskipun sudah diatur oleh manajemen rumah sakit.

Motivasi individu dipengaruhi oleh dua faktor yaitu faktor intrinsik dan faktor ekstrinsik. Faktor intrinsik meliputi prestasi, pengakuan diri, sifat pekerjaan tanggung jawab dan pengembangan karir sedangkan faktor ekstrinsik meliputi gaji, lingkungan kerja, hubungan kerja ${ }^{3}$. Teori Herzberg juga menyampaikan bahwa kinerja dipengaruhi oleh faktor motivator yang dimanifestasikan pada keberhasilan, penghargaan, tanggung jawab, pekerjaan, dan pengembangan diri. Teori ini menjelaskan bahwa dengan perubahan intrinsik faktor kepuasan kerja dapat dimotivasi. Sedangkan faktor ekstrinsik hanya merupakan faktor yang bersifat pencegah terjadinya ketidakpuasan kerja. ${ }^{4}$

Lingkungan kerja di RS Nur Hidayah juga kurang kondusif karena keterbatasan ruang bagi karyawan sehingga mengakibatkan karyawan kurang leluasa dalam menjalankan tugasnya. Menelaah latar belakang di atas maka peneliti tertarik untuk melakukan penelitian mengenai pengaruh motivasi terhadap kinerja karyawan di RS Nur Hidayah Kabupaten Bantul.

\section{METODE PENELITIAN}

Jenis penelitian ini adalah deskriptif dengan rancangan cross sectional. Penelitian ini dilakukan untuk mengetahui pengaruh motivasi terhadap kinerja karyawan di Rumah Sakit Nur Hidayah Kabupaten Bantul. Populasi dalam penelitian ini adalah seluruh karyawan RS Nur Hidayah yang berjumlah 111 orang.

Penelitian ini dilakukan dengan menggunakan instrumen kuesioner dan check list. Kuesioner digunakan untuk mengukur motivasi kerja. Sedangkan checklist digunakan untuk mengukur kinerja karyawan yang dilakukan oleh atasan masing- 
masing. Adapun teknik analisis menggunakan analisis univariat dan analisis bivariat. Analisis univariat digunakan untuk mengetahui frekuensi variabel-variabel yang akan diteliti dengan membuat rentang skor pada tiap variabel. Analisis bivariat digunakan untuk menguji hipotesis antara 2 variabel yang diduga memiliki pengaruh dengan menggunakan uji korelasi.

Tahap pengumpulan data dimulai dengan responden terlebih dahulu diberi penjelasan maksud dan tujuan penelitian ini. Pengumpulan data primer dilakukan dengan memberikan kuesioner secara langsung kepada responden dan ditunggu oleh peneliti sampai selesai. Checklist kinerja karyawan diisi oleh direktur, kepala bagian dan kepala sub bagian yang ada di rumah sakit dengan terlebih dahulu membuat perjanjian lama waktu pengisian karena tidak bisa diselesaikan dalam waktu yang singkat.

\section{HASIL PENELITIAN DAN PEMBAHASAN}

\section{a. Hasil Penelitian}

1) Karakteristik responden

Responden penelitian ini adalah seluruh karyawan RSKB Nur Hidayah Bantul yang berjumlah 111 karyawan yang sesuai dengan kriteria yang telah ditetapkan. Dari total tersebut hanya 79 karyawan yang bersedia menjadi responden dengan persentase sebesar $71 \%$.

Tabel 1. Karakteristik responden karyawan RS Nur Hidayah Bantul Tahun 2010

\begin{tabular}{lcc}
\hline \multicolumn{1}{c}{ Karakteristik } & Jumlah & Persentase (\%) \\
\hline Jenis Kelamin & & \\
- Laki-laki & 31 & 39,2 \\
- Perempuan & 48 & 60,8 \\
\hline Pendidikan & & \\
- SLTP/SLTA & 18 & 22,8 \\
- Diploma & 39 & 49,4 \\
- Sarjana/spesialis & 22 & 27,8 \\
\hline Lama Kerja & & \\
- <3 tahun & 52 & 65,8 \\
- 3-5 tahun & 10 & 12,7 \\
- >5 tahun & 17 & 21,5 \\
\hline
\end{tabular}




\begin{tabular}{lll}
\hline Status kepegawaian & & \\
- Tetap & 61 & 77,2 \\
- Tidak tetap & 18 & 22,8 \\
\hline Jarak rumah & \\
- <5 KM & 27 & 34,2 \\
- 5-10 KM & 27 & 34,2 \\
- >10 KM & 25 & 31,6 \\
\hline Status pernikahan & \\
- Menikah & 53 & 67,1 \\
- Belum menikah & 26 & 32,9 \\
\hline
\end{tabular}

Pada penelitian ini menunjukkan bahwa jenis kelamin perempuan lebih banyak dibanding laki-laki. Sedangkan pada tingkat pendidikan disebutkan bahwa pendidikan diploma menjadi yang terbanyak. Dari tingkat lama kerja didapat bahwa sebagian besar responden baru bekerja kurang dari 3 tahun. Sebagian besar responden berstatus sebagai karyawan tetap atau purna waktu. Dilihat dari status pernikahan menunjukkan bahwa sebagian besar responden sudah menikah.

Tabel 2. Data frekuensi profesi responden karyawan RS Nur Hidayah Bantul tahun 2010

\begin{tabular}{lcc}
\hline \multicolumn{1}{c}{ Profesi } & Frekuensi $(\mathrm{n})$ & Persentase \\
\hline Perawat/Asisten perawat & 27 & 34,2 \\
Dokter & 11 & 13,9 \\
Administrasi & 11 & 13,9 \\
Pemeliharaan/keamanan & 8 & 10,1 \\
Kerumah tanggaan & 7 & 8,9 \\
Apoteker/Asisten apoteker & 6 & 7,6 \\
Analis kesehatan & 4 & 5,1 \\
Radiografer & 3 & 3,8 \\
Bidan & 2 & 2,5 \\
\hline Jumlah total & 79 & 100 \\
\hline
\end{tabular}

Dari Tabel 2, dapat dilihat bahwa mayoritas responden dalam penelitian ini yaitu perawat/asisten perawat. Kemudian diikuti dokter dan pegawai administrasi. 
2) Analisis univariat

Tabel 3. Frekuensi variabel motivasi dan kinerja karyawan RS Nur Hidayah Bantul tahun 2010

\begin{tabular}{lcc}
\hline \multicolumn{1}{c}{ Variabel } & Jumlah $(\mathrm{n})$ & Persentase $(\%)$ \\
\hline Motivasi & & \\
- Tinggi & 65 & 82,3 \\
- Sedang & 14 & 17,7 \\
Kinerja & & \\
- Tinggi & 73 & 92,4 \\
- Sedang & 6 & 7,6 \\
\hline
\end{tabular}

Berdasarkan Tabel 3, Sebagian besar motivasi kerja karyawan RS Nur Hidayah berada dalam kategori tinggi. Tidak ada karyawan yang masuk dalam kategori rendah. Sedangkan untuk kinerja menunjukkan bahwa sebagian besar karyawan mempunyai kinerja yang tinggi dengan persentase mencapai 92,4\% dan hanya $7,6 \%$ karyawan yang mempunyai kinerja sedang. Tidak ada karyawan yang masuk dalam kategori kinerja rendah.

Tabel 4. Frekuensi sub variabel motivasi intrinsik dan motivasi ekstrinsik karyawan RS Nur Hidayah Bantul tahun 2010

\begin{tabular}{lcc}
\hline Variabel & Jumlah $(\mathrm{n})$ & Persentase (\%) \\
\hline Motivasi Intrinsik & & \\
- Tinggi & 58 & 73,4 \\
- Sedang & 21 & 26,6 \\
\hline Motivasi ekstrinsik & & \\
- Tinggi & 34 & 43 \\
- Sedang & 45 & 57 \\
\hline
\end{tabular}

Pada Tabel 4, dilihat bahwa faktor motivasi intrinsik mayoritas karyawan RSKB Nur Hidayah Bantul termasuk dalam kategori tinggi dengan persentase $73,4 \%$. Faktor Motivasi ekstrinsik dengan kategori tinggi juga cukup tinggi dengan persentase $43 \%$ meskipun lebih rendah dibanding kategori sedang yang mencapai $57 \%$.

3) Analisis bivariat

Tabel 5. Pengaruh motivasi kerja terhadap kinerja karyawan Rumah Sakit Nur Hidayah Bantul tahun 2010

\begin{tabular}{lcc}
\hline Variabel & \multicolumn{2}{c}{ Kinerja Karyawan } \\
\cline { 2 - 3 } & $\mathrm{R}$ & Sig(p) \\
\hline Motivasi kerja & 0,775 & 0,00 \\
\hline
\end{tabular}


Pada Tabel 5 dapat diketahui koefisien korelasi ( $r$ ) sebesar 0,775 dengan signifikan (p) 0,00 lebih kecil dari $(0,05)$. Maka disimpulkan ada pengaruh yang kuat antara motivasi terhadap kinerja karyawan RSKB Nur Hidayah Bantul.

Tabel 6. Pengaruh motivasi intrinsik dan motivasi ekstrinsik terhadap kinerja karyawan Rumah Sakit Nur Hidayah Bantul 2010

\begin{tabular}{lcc}
\hline \multicolumn{1}{c}{ Variabel } & \multicolumn{2}{c}{ Kinerja Karyawan } \\
\cline { 2 - 3 } & $\mathrm{R}$ & $\operatorname{Sig}(\mathrm{p})$ \\
\hline Motivasi Intrinsik & 0,737 & 0,00 \\
Motivasi Ekstrinsik & 0,325 & 0,03 \\
\hline
\end{tabular}

Faktor motivasi intrinsik dan ekstrinsik yang digambarkan pada tabel 6 diatas memberikan informasi mengenai motivasi intrinsik memiliki nilai koefisien korelasi (r) sebesar 0,737 dengan signifikan (p) 0,00 lebih kecil dari $(0,05)$, maka disimpulkan ada pengaruh kuat motivasi intrinsik terhadap kinerja karyawan RSKB Nur Hidayah Bantul. Sedangkan antara motivasi ekstrinsik dengan kinerja karyawan terdapat pengaruh yang rendah dengan koefisien korelasi ( $r$ ) sebesar 0,325 .

Tabel 7. Pengaruh sub variabel motivasi intrinsik terhadap kinerja karyawan Rumah Sakit Nur Hidayah Bantul tahun 2010

\begin{tabular}{lcc}
\hline \multicolumn{1}{c}{ Variabel } & \multicolumn{2}{c}{ Kinerja Karyawan } \\
\cline { 2 - 3 } & $\mathrm{R}$ & $\mathrm{Sig}(\mathrm{p})$ \\
\hline Motivasi Intrinsik & & \\
- Tanggung jawab & 0,242 & 0,032 \\
- Pengakuan & 0,349 & 0,002 \\
- Prestasi kerja & 0,301 & 0,007 \\
- Pengembangan karir & 0,505 & 0,000 \\
- Pekerjaan & 0,270 & 0,016 \\
- Promosi & 0,246 & 0,029 \\
\hline
\end{tabular}

Pada Tabel 7, dapat diketahui sub variabel motivasi intrinsik didapat pengaruh yang sedang antara pengembangan karir terhadap kinerja karyawan dengan koefisien korelasi $(r)$ sebesar 0,505 . Sedangkan sub variabel motivasi intrinsik lainnya menunjukkan pengaruh yang rendah terhadap kinerja karyawan yaitu pengakuan $(r=0,349)$, prestasi kerja $(r=0,301)$, pekerjaan $(r=0,270)$, promosi $(r=0,246)$ dan tanggung jawab didapat nilai $(r)$ sebesar 0,242 . 
Tabel 8. Pengaruh sub variabel motivasi ekstrinsik terhadap kinerja karyawan Rumah Sakit Nur Hidayah Bantul tahun 2010

\begin{tabular}{lcc}
\hline \multirow{2}{*}{ Variabel } & \multicolumn{2}{c}{ Kinerja Karyawan } \\
\cline { 2 - 3 } & $\mathrm{R}$ & $\operatorname{Sig}(\mathrm{p})$ \\
\hline Motivasi Ekstrinsik & & \\
- Kondisi kerja & 0,375 & 0,001 \\
- Hubungan kerja & 0,086 & 0,453 \\
- Gaji & 0.098 & 0.388 \\
\hline
\end{tabular}

Pada Tabel 8 menunjukkan pengaruh antara sub variabel motivasi ekstrinsik karyawan terhadap kinerja karyawan. Subvariabel kondisi kerja memiliki pengaruh yang rendah terhadap kinerja karyawan dengan koefisien korelasi ( $r$ ) sebesar 0,375 . Sedangkan untuk sub variabel hubungan kerja dan gaji tidak memiliki pengaruh terhadap kinerja karyawan di RS Nur Hidayah Bantul.

\section{b. Pembahasan}

Eratnya pengaruh motivasi kerja terhadap kinerja karyawan harus memperoleh perhatian khusus bagi pihak manajemen. Karena kinerja karyawan yang baik juga dapat menjadi salah satu faktor meningkatnya kinerja rumah sakit karena karyawan menjadi pintu utama dalam pelayanan kesehatan kepada masyarakat. Motivasi kerja yang tinggi menjadikan para karyawan mempunyai semangat yang tinggi untuk memberikan pelayanan yang terbaik bagi pasien sehingga pasien merasa puas dengan pelayanan yang diberikan. Perlu upaya untuk mempertahankan motivasi kerja para karyawan agar tetap berada pada level yang tinggi sehingga akan berdampak positif bagi perkembangan rumah sakit kedepan. Karyawan akan termotivasi apabila keinginan serta kebutuhan mereka terpenuhi. Terdapat hubungan yang kuat antara motivasi dengan kinerja, semakin tinggi motivasi kerja maka akan semakin baik kinerja yang dihasilkan. ${ }^{5}$

Jika dilihat dari masing-masing sub variabel motivasi intrinsik dan ekstrinsik menghasilkan berbagai variasi. Sub variabel motivasi intrinsik yang terdiri dari tanggung jawab, pengakuan, prestasi kerja, pengembangan karir, pekerjaan dan promosi didapat hasil secara umum semua sub variabel motivasi intrinsik mempunyai pengaruh terhadap kinerja karyawan. Faktor motivasi intrinsik berupa peluang untuk memperoleh pendidikan/pengembangan karir, luasnya pekerjaan yang diterima merupakan faktor penting bagi dokter untuk meningkatkan kinerjanya yang berujung pada tingkat kepuasan kerja ${ }^{6}$. Faktor intrinsik motivasi dapat mempengaruhi peluang untuk promosi yang dapat meningkatkan kinerja seseorang karena kinerja seseorang salah satunya diukur dari peluang mereka untuk promosi. ${ }^{7}$

Pada umumnya ada pengaruh kuat motivasi kerja terhadap kinerja karyawan. Hasil yang sama juga idapat dari penelitian yang berbeda bahwa terdapat hubungan positif motivasi kerja dengan kinerja perawat, semakin tinggi motivasi maka semakin baik pula kinerja mereka ${ }^{8}$. Kondisi kerja menjadi sub variabel terpenting faktor ekstrinsik motivasi yang dapat mempengaruhi kinerja karyawan. Perlu ada perhatian untuk kondisi kerja para karyawan supaya motivasi kerja mereka dapat terjaga dengan baik. Kondisi kerja sangat dipengaruhi dengan ketersediaan dan 
berfungsinya peralatan, kenyamanan dan keamanan tempat kerja. Semakin baik kondisi kerja, hubungan kerja dan gaji karyawan dapat menjaga karyawan untuk tetap termotivasi dalam menjalankan tugasnya masing-masing. Dari semua penjelasan diatas maka faktor-faktor motivasi intrinsik perlu lebih diperhatikan karena memiliki pengaruh yang lebih kuat dibanding faktor-faktor motivasi ekstrinsik dalam meningkatkan motivasi kerja karyawan. Sedangkan motivasi ekstrinsik hanya sebatas untuk menjaga motivasi kerja karyawan supaya tetap bekerja dengan baik. Karena semakin tinggi motivasi intrinsik maka akan semakin baik kinerja karyawan. Para karyawan menganggap bahwa tanggung jawab, pengakuan, prestasi kerja, pengembangan karir, pekerjaan, kesempatan promosi lebih penting dalam meningkatkan mereka agar tetap terus termotivasi dalam bekerja dibanding faktor kondisi kerja, hubungan kerja dan gaji. Penelitian yang sama menyatakan bahwa aspek pekerjaan dan kesempatan promosi mempengaruhi seseorang untuk tetap bekerja disana serta dapat mempengaruhi kepuasan kerja yang dapat meningkatkan kinerja perawat. $^{9}$

\section{SIMPULAN DAN SARAN}

\section{a. Simpulan}

Ada pengaruh motivasi kerja terhadap kinerja karyawan di RS Nur Hidayah Bantul. Ada pengaruh faktor motivasi intrinsik dan motivasi ekstrinsik terhadap kinerja karyawan di RS Nur Hidayah Bantul. Ada pengaruh sub variabel motivasi intrinsik (tanggung jawab, pengakuan, prestasi kerja, pengembangan karir, pekerjaan, promosi) terhadap kinerja karyawan di RS Nur Hidayah Bantul. pengembangan karir memiliki pengaruh tertinggi dibandingkan dengan sub variabel motivasi intrinsik lainnya. Tidak ada pengaruh sub variabel motivasi ekstrinsik (hubungan kerja dan gaji) terhadap kinerja karyawan di RS Nur Hidayah Bantul. Ada pengaruh sub variabel kondisi kerja dalam motivasi ekstrinsik terhadap kinerja karyawan di RS Nur Hidayah Bantul.

\section{b. Saran}

Dari hasil penelitian ini maka kami menyarankan kepada pihak manajemen rumah sakit untuk terus mempertahankan tingkat motivasi karyawan yang sudah tinggi dan meningkatkan motivasi karyawan. Motivasi intrinsik harus lebih diperhatikan dalam upaya meningkatkan motivasi kerja. Memberikan kesempatan yang lebih luas bagi karyawan untuk terus berkembang dan mendapat peluang yang lebih terbukan untuk promosi. Memperbaiki kondisi kerja rumah sakit agar karyawan merasa aman dan nyaman dalam bekerja. Meningkatkan dukungan dari atasan, terutama atas kemajuan dan keberhasilan karyawan.

Maka kinerja karyawan akan tetap berada pada level tertinggi yang dapat berdampak positif terhadap perkembangan rumah sakit kedepan. Diharapkan juga untuk terus dilakukan penelitian pengaruh motivasi dan beban kerja terhadap kinerja agar pelayanan kesehatan dapat terus terjaga dengan baik. 


\section{DAFTAR PUSTAKA}

1. Samba, S. Pengantar kepemimpinan \& manajemen keperawatan untuk perawat klinis. Jakarta. EGC.(2000)

2. Handoko, T.H. Manajemen personalia \& sumber daya manusia. Yogyakarta. BPFE. (2008)

3. Handoko, T.H. Manajemen. Yogyakarta. BPFE.(2009)

4. Ilyas, Y. Kinerja : teori, penilaian, dan penelitian. Depok. Pusat Kajian Ekonomi Kesehatan FKM UI.(2002)

5. Badi'ah, A. Mendri, N.K. Ratna, W. Hendarsih, S. Sutrisno. Lena, I.A. Rosyidah. Hubungan motivasi perawat dengan kinerja perawat di ruang rawat inap Rumah Sakit Daerah Panembahan Senopati Bantul tahun 2008. Jurnal manajemen pelayanan kesehatan, Juni, hal 74-82.(2009)

6. Janus, K. Amelung. V. Baker, LC. Gaitanides, M. Schwartz, F. Rundall, T. Job satisfaction and motivation among physicians in academic medical center : insights from a cross-national study .Journal of Health Politics, Policy and Law Vol 33 no 6, 11331167.(2008)

7. Herpen, Marco.V. Praag, Mirjaam.V. Cools, Kees. The effects of performance measurement and compensation on motivation : an empirical study. De Economist Journal 153, 303-329.(2005)

8. Wahyuni, I. Hubungan antara motivasi, kelelahan kerja dan kepuasan kerja pada perawat RSJD. DR. RM. Soedjarwadi Klaten. Tesis, Universitas Gadjah Mada.(2005)

9. Kunaviktikul, W. Nuntasupawat, R. Srisuphan, W. Booth, RZ. Relationship among conflict, conflict management, job satisfaction, intent to stay, and turn over of professional nurses in Thailand. Nursing and Health Service Journal, 2, 9-16.(2000) 